\title{
PROPAGAÇÃO VEGETATIVA DE Platanus acerifolia Ait: (II) EFEITO DA APLICAÇÃO DE ZINCO, BORO E ÁCIDO INDOLBUTÍRICO NO ENRAIZAMENTO DE ESTACAS ${ }^{1}$
}

\section{VEGETATIVE PROPAGATION OF Platanus acerifolia Ait: (II) EFFECT OF ZINC, BORON, AND INDOLBUTIRIC ACID ON ROOTING OF CUTTINGS}

\author{
Fernando Teixeira Nicoloso ${ }^{2}$ Marcondes Lazzari $^{3}$ Roni Paulo Fortunato ${ }^{4}$
}

RESUMO

\begin{abstract}
O objetivo desse trabalho foi avaliar os efeitos da aplicação do zinco $(Z n)$, boro $(B)$ e ácido indolbutírico $(A I B)$ no enraizamento de estacas de Platanus acerifolia Ait. Os tratamentos consistiram do condicionamento das estacas, coletadas em quatro épocas ao longo do ano e representando diferentes tipos fisiológicos, com: sulfato e cloreto de zinco $(0,2,5,5,10,20$ e 40mg $\left.l^{-1} \mathrm{Zn}\right)$, ácido bórico $\left(0,50,100,150,200\right.$ e 250mg $l^{-1}$ $\left.\mathrm{H}_{3} \mathrm{BO}_{3}\right)$ e ácido indolbutírico $\left(0,20\right.$ e $\left.40 \mathrm{mg}^{l^{-1}} \mathrm{AIB}\right)$, através de solução aquosa, pela imersão de $3 \mathrm{~cm}$ da base da estaca, com duas lesões laterais de $2 \mathrm{~cm}$, por 24 horas. A estaquia foi feita em vasos contendo como substrato uma mistura de areia média e casca de arroz carbonizada $(1: 1, v / v)$, ambas lavadas. O experimento foi conduzido por 110 dias em casa de vegetação com aspersão intermitente. No encerramento do experimento, avaliaram-se os seguintes parâmetros: comprimento e número de raízes primárias por estaca, máteria seca de raízes por estaca e percentagem de enraizamento. A aplicação isolada de Zn e B não influencia o enraizamento das estacas. $O$ condicionamento de estacas de ramos "do ano" basais finas com AIB afeta, negativamente, o percentual de enraizamento e, positivamente, o número de raízes por estaca.
\end{abstract}

Palavras-chave: estaquia, Platanus acerifolia, boro, zinco, ácido indolbutírico, tipos fisiológicos, enraizamento.

\section{SUMMARY}

The aim of this work was to evaluate the effects of zinc $(Z n)$, boron $(B)$, and indolbutiric acid (IBA) on rooting of Platanus acerifolia Ait. cuttings. The treatments of the cuttings,

\begin{abstract}
which were collected at four different times during the year and representing four physiological types of cuttings, were: zinc sulphate and chloride $\left(0,2,5,5,10,20\right.$, and $\left.40 \mathrm{mg} l^{-1} \mathrm{Zn}\right)$, boric acid $\left(0,50,100,150,200\right.$, and $\left.250 \mathrm{mg}^{-1} \mathrm{H}_{3} \mathrm{BO}_{3}\right)$, and indolbutiric acid $\left(0,20\right.$, and $\left.40 m g l^{-1} I B A\right)$. The treatments with $B, Z n$ and IBA were done through submersion of $3 \mathrm{~cm}$ of the cutting basis, during 24 hours, in an aqueous solution. The cuttings were rooted in pots containing as substrate a mixture of medium sand + carbonised rice husk, $1: 1 \mathrm{v} / \mathrm{v}$, both washed. The experiment was conducted during 110 days under intermittent artificial mist conditions. The evaluated parameters were: length and number of primary adventitious roots, dry weight of adventitious roots, and percentage of rooting. The results show that $Z n$ and $B$ have no influence on the rooting, and the addition of IBA on thin basal semi-herbaceous cuttings reduces the percentage of rooting and increase the number of roots.
\end{abstract}

Key words: cuttings, Platanus acerifolia, type of cuttings, boron, zinc indolburic acid, rooting.

\section{INTRODUÇÃO}

O plátano híbrido (Platanus acerifolia Ait.) é uma espécie florestal muito difundida, especialmente como árvore ornamental na arborização de ruas, parques e praças, bem como pela qualidade de sua madeira empregada na carpintaria, fabricação de móveis e pisos, sendo também utlizada como quebra-vento (LEONARDIS, 1977; MERINO, 1991; ONO et al., 1994).

\footnotetext{
${ }^{1}$ Projeto Financiado pela Fundação de Incentivo à Pesquisa e Ensino (FIPE) - Universidade Federal de Santa Maria (UFSM) e FAPERGS

${ }^{2}$ Engenheiro Agrônomo, PhD., Professor Adjunto do Departamento de Biologia, Centro de Ciências Naturais e Exatas (CCNE), UFSM, 97105-900. Santa Maria, RS. E-mail: nicoloso@ sm.conex.com.br. Autor para correspondência.

${ }^{3}$ Engenheiro Agrônomo, Mestre em Agronomia.

${ }^{4}$ Acadêmico do Curso de Agronomia, UFSM, Bolsista da FAPERGS 
Devido à baixa percentagem de germinação das sementes de plátano, o principal método de propagação utilizado para a espécie vem sendo a estaquia.

Tem sido observado que a formação de raízes adventícias se deve à interação de fatores existentes nos tecidos e da translocação de substâncias sintetizadas nas folhas e gemas em desenvolvimento. Entre estes fatores, os fito-hormônios, nutrientes minerais e auxinas sintéticas são de fundamental importância (WANG \& ANDERSEN, 1989; HENRY et al., 1992; FACHINELLO et al., 1994).

A composição mineral de uma planta influencia o seu comportamento morfofisiológico. O Zn é requerido na síntese do triptofano, um precursor do ácido indolacético, que é um fito-hormônio envolvido na formação de raízes adventícias (MENGEL \& KIRKBY, 1979; BLAKESLEY et al., 1990). Apesar disso, e de sua comprovada essencialidade em outros processos metabólicos da planta, pouca atenção até o presente momento foi dispensada ao seu possível uso como co-fator importante no enraizamento, podendo até mesmo substituir a utilização de auxinas sintéticas.

Quanto ao B, tem-se observado que na sua deficiência aparecem vários distúrbios prejudiciais ao desenvolvimento dos tecidos meristemáticos, como morte dos ápices das raízes e tecidos do câmbio (MENGEL \& KIRKBY, 1979). MIDDLETON et al. (1978) sugerem que a iniciação de raízes nas estacas é estimulada pela auxina, devendo-se o posterior crescimento ao B. HENRY et al. (1992) observaram correlação significativa entre níveis de B e potássio encontrados nas estacas de Juniperus virginiana L. e a resposta ao enraizamento.

Entre as substâncias reguladoras do crescimento utilizadas em estaquia, as auxinas são as que apresentam maior efeito positivo na formação de raízes adventícias. O teor adequado a ser aplicado depende da espécie vegetal e da concentração de fito-hormônios existentes nos tecidos. Quanto ao tipo de auxina, têm-se observado diferenças marcantes sobre o enraizamento. $\mathrm{O}$ ácido indolbutírico (AIB) e o ácido naftaleno acético mostram-se, na maioria dos casos testados, mais eficientes do que o ácido indolacético (TERRA et al., 1981; ALVARENGA \& CARVALHO, 1983; FACHINELLO et al. 1994).

Considera-se que o estudo dos aspectos mencionados pode maximizar significativamente a percentagem de enraizamento do plátano e, conseqüentemente, colocar a estaquia como método economicamente viável aos viveiristas. Portanto, o objetivo deste trabalho foi estudar os efeitos da aplicação do Zn, B e AIB no enraizamento de estacas de ramos de plátano.

\section{MATERIAL E MÉTODOS}

O trabalho foi conduzido na Universidade Federal de Santa Maria (UFSM), Santa Maria - RS. A condução dos experimentos foi realizada na casa de vegetação do Departamento de Ciências Florestais.

O material vegetativo utilizado no experimento proveio de cinco árvores matrizes de plátano, com idade aproximada de 30 anos, e obtidas via estaquia, localizadas próximo à UFSM. Foram utilizadas estacas com comprimento médio de $20 \mathrm{~cm}$, sem folhas, possuindo três a quatro gemas. Após a coleta e obtenção das estacas, fez-se o condicionamento pela aplicação de $\mathrm{B}, \mathrm{Zn}$ e AIB, realizado através de solução aquosa, pela imersão de $3 \mathrm{~cm}$ da base da estaca, com duas lesões laterais de $2 \mathrm{~cm}$, por 24 horas, seguindo a recomendação de FACHINELLO et al. (1994). Os tratamentos utilizados foram obtidos da variação dos seguintes fatores: época de coleta dos ramos, tipo fisiológico da estaca e adição de B, Zn e AIB. A descrição detalhada dos fatores época de coleta e tipo fisiológico da estaca foram descritos no trabalho precedente (NICOLOSO et al., 1999) e dos níveis de B, Zn e AIB estão na tabela 1 .

O estaqueamento foi realizado em vasos de plástico, com capacidade para 1,6 litros. Como substrato, utilizou-se uma mistura de areia média de rio e casca de arroz carbonizada, ambas lavadas, na proporção de 1:1 (v/v). Colocaram-se três estacas por vaso, introduzindo $2 / 3$ do seu comprimento no substrato.

A condução do experimento foi realizada em casa de vegetação, por período de 110 dias, onde, além da água fornecida por aspersão, forneceram-se $150 \mathrm{ml}$ de água/vaso diariamente, sempre que a temperatura do ar ultrapassava $25^{\circ} \mathrm{C}$. Na instalação e no decorrer do experimento, fez-se tratamento antifúngico com Benlate (benomyl), na dose de 0,6g $1^{-1}$, a cada 2 semanas.

O delineamento experimental utilizado foi inteiramente casualizado com quatro repetições por tratamento, contendo cada repetição três estacas. Cada repetição correspondeu a um vaso. Os parâmetros avaliados no encerramento do experimento foram os seguintes: número de raízes primárias por estaca, comprimento das raízes primárias por estaca, matéria seca de raízes por estaca e percentagem de estacas enraizadas

A análise estatística dos tratamentos B, $\mathrm{Zn}$ e AIB+B foi realizada por análise de regressão, com significância em nível de probabilidade de erro de $5 \%$. 
Tabela 1 - Descrição dos níveis de B, Zn e AIB utilizados no enraizamento de quatro tipos fisiológicos de estacas de ramos de plátano (Platanus acerifolia Ait.), coletadas em quatro épocas ao longo do ano. Santa Maria, RS, 1998.

\begin{tabular}{|c|c|c|c|c|}
\hline $\begin{array}{l}\text { Época } \\
\text { e coleta }\end{array}$ & $\begin{array}{c}\text { Tipo fisiológico } \\
\text { da estaca }\end{array}$ & Adição de B & adição de $\mathrm{Zn}$ & adição de AIB \\
\hline $\begin{array}{c}\mathrm{I} \\
(\text { Setembro/95) }\end{array}$ & $\begin{array}{l}\text { - "de ano"*11 } \\
\text { - "do ano"*1 }\end{array}$ & $\begin{array}{l}\text { Todos os tipos de estacas } \\
\text { foram tratados com } \mathrm{B} \text {, nas } \\
\text { seguintes concentrações: } \\
0,50,100,150,200 \text { e } \\
250 \mathrm{mg} \mathrm{l}^{-1} \mathrm{H}_{3} \mathrm{BO}_{3}\end{array}$ & $\begin{array}{l}\text { Utilizou-se, em todos os tipos } \\
\text { de estacas, como fonte de } \mathrm{Zn} \text {, } \\
\text { o sal; } \mathrm{ZnSO}_{4} .7 \mathrm{H}_{2} \mathrm{O} \text { nas se- } \\
\text { guintes concentrações: } 0,2,5 \text {, } \\
10 \text { e } 20 \mathrm{mg} \mathrm{l}^{-1} \mathrm{Zn} \text {. }\end{array}$ & - \\
\hline $\begin{array}{c}\text { II } \\
\text { (Janeiro/96) }\end{array}$ & $\begin{array}{l}\text { - "de ano"*1 } \\
\text { - "do ano": } \\
\text { basal; e } \\
\text { mediana }\end{array}$ & $\begin{array}{l}\text { Todos os tipos de estacas } \\
\text { foram tratados com } \mathrm{B} \text {, nas } \\
\text { seguintes concentrações: } \\
0,50,100,150,200 \text { e } \\
250 \mathrm{mg} \mathrm{l}^{-1} \mathrm{H}_{3} \mathrm{BO}_{3}\end{array}$ & - & - \\
\hline $\begin{array}{c}\text { III } \\
(\text { Março/96) }\end{array}$ & $\begin{array}{l}\text { - "de ano"*1 } \\
\text { - "do ano": } \\
\text { basal; e } \\
\text { mediana }\end{array}$ & $\begin{array}{l}\text { Todos os tipos de estacas } \\
\text { foram tratados com } \mathrm{B} \text {, nas } \\
\text { seguintes concentrações: } \\
0,50,100,150,200 \text { e } \\
250 \mathrm{mg} \mathrm{l}^{-1} \mathrm{H}_{3} \mathrm{BO}_{3}\end{array}$ & $\begin{array}{l}\text { Utilizaram-se como fonte de } \\
\mathrm{Zn} \text {, em estacas de ramos "do } \\
\text { ano" basal, dois sais: } \\
\mathrm{ZnSO}_{4} .7 \mathrm{H}_{2} \mathrm{O} \text { e } \mathrm{ZnCl}_{2} \text {; nas } \\
\text { seguintes concentrações: } 0 \text {, } \\
2,5,10,20 \text { e } 40 \mathrm{mg} \mathrm{l}^{-1} \mathrm{Zn} \text {. }\end{array}$ & $\ldots$ \\
\hline $\begin{array}{c}\text { IV } \\
\text { (Julho/96) }\end{array}$ & $\begin{array}{l}\text { - "do ano": } \\
\text { basal fina; } \\
\text { basal; e } \\
\text { mediana }\end{array}$ & $\begin{array}{l}\text { Todos os tipos de estacas } \\
\text { foram tratados com } \mathrm{B} \text {, nas } \\
\text { seguintes concentrações: } \\
0,50,100,150,200 \text { e } \\
250 \mathrm{mg} \mathrm{l}^{-1} \mathrm{H}_{3} \mathrm{BO}_{3}\end{array}$ & & $\begin{array}{l}\text { Aplicação de AIB em todos os } \\
\text { tipos de estacas nas concen- } \\
\text { trações de: } 0,20 \text { e } 40 \mathrm{mg} \mathrm{l}^{-1} \text {, } \\
\text { combinadas em um fatorial } \\
\text { completo com B nas concen- } \\
\text { trações: } 0,50 \text { e } 100 \mathrm{mg}^{-1} \\
\mathrm{H}_{3} \mathrm{BO}_{3} \text {. }\end{array}$ \\
\hline
\end{tabular}

*11 Não se fez distinção das estacas quanto à posição que ocupavam no ramo.

\section{RESULTADOS E DISCUSSÃO}

\section{Condicionamento com zinco}

Verificou-se que, independentemente do tipo fisiológico da estaca e da sua época de coleta, a aplicação de Zn através de dois sais diferentes não alterou significativamente nenhuma das variáveis do crescimento analisadas.

O Zn é requerido na síntese do triptofano, precursor do AIA (ácido indolacético), sendo este um fito-hormônio envolvido na formação de raízes adventícias (MENGEL \& KIRKBY, 1979; BLAKESLEY et al., 1990). Portanto, esperava-se que a aplicação de $\mathrm{Zn}$, como condicionamento, melhorasse o enraizamento pelo aumento da concentração de AIA nas estacas.

KERSTEN (1990) estudou o efeito de Zn, aplicado via solo, no enraizamento de estacas de ameixeira (Prunus salicina Lindl.) coletadas em quatro épocas do ano. A percentagem de enraizamento observada em dezembro foi significativamente menor nas estacas oriundas de plantas tratadas com Zn. Quanto ao número de raízes por estaca, analisado exclusivamente em março, o tratamento testemunha teve resultado significativamente maior do que naquelas onde se fez aplicação de Zn. Já naquelas de dezembro e de fevereiro, as estacas de plantas tratadas com $\mathrm{Zn}$ não diferiram daquelas não tratadas, quanto a produção de matéria seca de raízes.

LAZZARI et al. (1996a) também utilizando como substrato areia + casca de arroz carbonizada $(1: 1, v / v)$, verificaram que a formação de calosidade, que antecede a formação das raízes de estacas de pessegueiro (Prunus persica) cv. Coral e Vila-Nova, diminuiu significativamente pela aplicação de $\mathrm{Zn}$ na forma de solução aquosa, a partir da dose de $50 \mathrm{mg}^{-1}$ até $100 \mathrm{mg} \mathrm{l}^{-1}$. Em outro sistema experimental, LAZZARI et al. (1996b) constataram que o tratamento das estacas de salso bugre (Salix humboldtidiana) com $\mathrm{Zn}$ reduziu linearmente, até a dose de $200 \mathrm{mg} \mathrm{l}^{-1}$, o comprimento das raízes adventícias, bem como o número de raízes por estaca. Esta diferença, observada para essas duas espécies, em contraste com o plátano, pode estar relacionada à concentração de $\mathrm{Zn}$ aplicada. 


\section{Condicionamento com boro}

A percentagem de estacas enraizadas não foi influenciada pelo condicionamento com B. Dentre os parâmetros do crescimento do sistema radicular avaliados, o único que foi afetado significativamente pela adição de $\mathrm{B}$ foi o número de raízes primárias. Em função desse resultado ter sido observado apenas para estacas de ramos "do ano" medianas (figura 1), coletadas em março, torna-se difícil sugerir alguma explicação plausível.

KERSTEN (1990) avaliou o enraizamento de estacas de ameixeira (Prunus salicina Lindl.) cv. Carmesim e Grancuore, coletadas em quatro épocas (maio, novembro, dezembro e fevereiro), em relação à aplicação de B às plantas matrizes. No cultivar Carmesim, houve diferença significativa apenas naquelas coletadas em dezembro, onde as plantas não tratadas com $\mathrm{B}$ produziram estacas que tiveram percentual de enraizamento superior àquelas tratadas. Para número de raízes por estaca, determinado somente em maio, o autor não observou diferença significativa entre estacas das plantas testemunhas e estacas das plantas tratadas com B. Já em dezembro e fevereiro, as estacas oriundas de plantas tratadas com B acumularam significativamente mais matéria seca de raízes que aquelas das plantas testemunhas.

Segundo GAUCH \& DUGGER (1954), as folhas de plantas deficientes em B apresentam, comparativamente, maiores concentrações de açúcares, contudo a concentração nos ramos é baixa, indicando que o teor de B influencia a translocação dos fotossintatos. Portanto, um nível adequado de B nas estacas aumentaria a disponibilidade de carboidratos aos loci meristemáticos, possibilitando maior crescimento das raízes. Assim, era de se esperar efeito positivo do B no comprimento das raízes primárias e, ainda, na produção de matéira seca, como observou KERSTEN (1990).

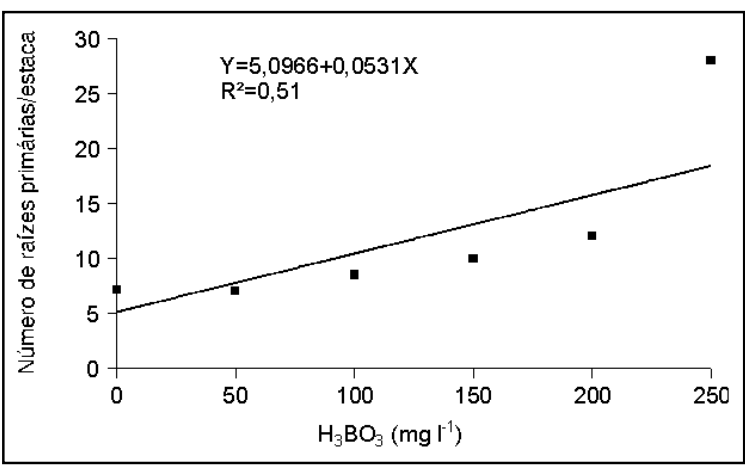

Figura 1- Efeito da aplicação de B no número de raízes primárias de estacas de ramos "do ano" medianas de plátano (Platanus acerifolia Ait.), coletadas na época III (março/96). Santa Maria, RS, 1998.
Outros pontos que devem ser considerados para os presentes resultados são os seguintes: (i) existência de níveis adequados de $\mathrm{B}$ nos tecidos das estacas; (ii) deficiência na absorção do $\mathrm{B}$ adicionado na forma de solução aquosa; (iii) liberação de B a partir da casca de arroz carbonizada e lavada.

\section{Condicionamento com boro + ácido indolbutírico}

A percentagem de enraizamento de estacas de ramos "do ano" basais finas decresceu linearmente à medida que aumentaram as doses de AIB, mantendo-se constante a de $\mathrm{B}$ em $100 \mathrm{mg} \mathrm{l}^{-1} \mathrm{H}_{3} \mathrm{BO}_{3}$ (figura 2a). Isto sugere que, provavelmente, as estacas obtidas de ramos menos desenvolvidos já tenham teor de auxina endógena suficiente ao enraizamento, devido à sua maior atividade meristemática (FACHINELLO et al., 1994). Além disso, segundo FERRI (1979), altas doses de AIB podem ter efeito fitotóxico mesmo em estacas com baixa concentração de auxinas.

FACHINELLO et al. (1984) observaram que os melhores resultados para percentagem de enraizamento em estacas de pessegueiro (Prunus persica L.) ocorreram entre 2000 e $3000 \mathrm{mg} \mathrm{kg}^{-1}$ AIB, aplicado na forma de pó, porém tendo efeito negativo na dose de $4000 \mathrm{mg} \mathrm{kg}^{-1}$. ONO et al.(1992a,

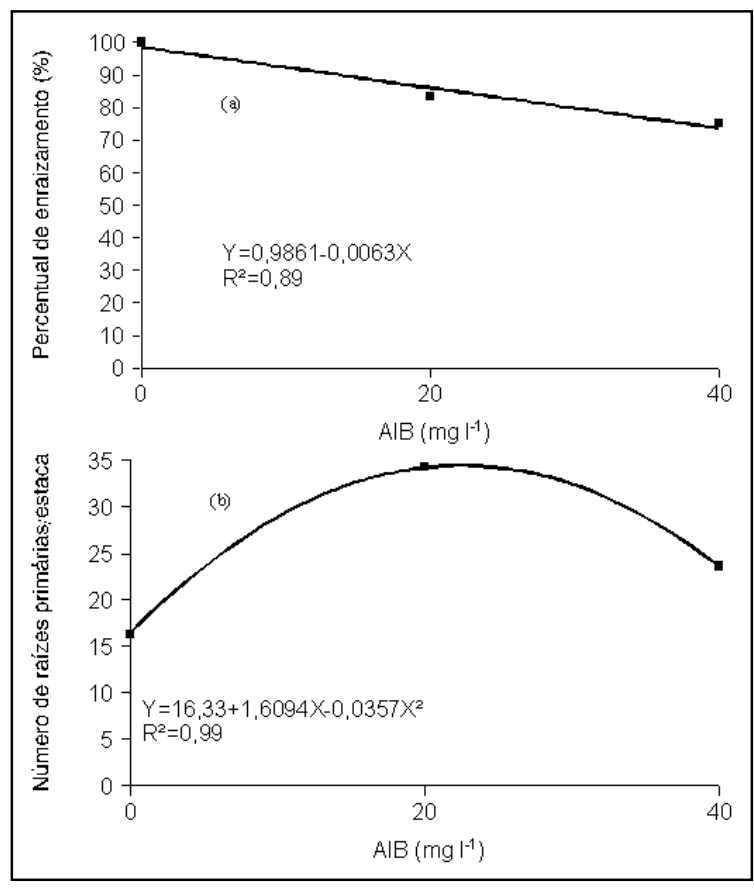

Figura 2- Efeito da aplicação de AIB no percentual de enraizamento (a) e no número de raízes primárias (b) de estacas de ramos "do ano" basais finas de plátano (Platanus acerifolia Ait.), tratadas com $100 \mathrm{mg} \mathrm{l}^{-1}$ de $\mathrm{H}_{3} \mathrm{BO}_{3}$, coletadas na época IV (julho/96). Santa Maria, RS, 1998. 
1992b; 1993) constataram sinergismo do B e AIB no enraizamento de café e camélia. Também MISRA \& JAUHARI (1970), trabalhando com estacas de Morus alba L., observaram resultados semelhantes, sendo que a melhor combinação foi a de $200 \mathrm{mg}^{-1}$ AIB e $25 \mathrm{mg} \mathrm{l}^{-1} \mathrm{H}_{3} \mathrm{BO}_{3}$.

$\mathrm{Na}$ avaliação do crescimento do sistema radicular dentre os três tipos fisiológicos de estacas testados, o único influenciado pela adição de AIB, para número de raízes, foi aquele "do ano" basal fina, apresentando resposta quadrática com ponto de máxima eficiência a 20 $\mathrm{mg} \mathrm{l}^{-1}$ AIB, (Figura 2b). Segundo BEZERRA et al. (1992), a aplicação exógena de auxinas pode ser fitotóxica aos ramos herbáceos, que contêm altas concentrações de AIA endógeno, justificando desse modo o decréscimo pela dose mais elevada de AIB.

Em função do estádio de desenvolvimento dos ramos que deram origem aos três tipos fisiológicos de estacas testados (NICOLOSO et al., 1999), esperava-se que aquelas "do ano" basais e medianas (menos herbáceas) respondessem mais à aplicação do AIB do que as "do ano" basais finas (mais herbáceas).

O comprimento das raízes primárias em estacas de ramos "do ano" medianas diminuiu linearmente pelo aumento das doses de AIB (Figura 3). Este resultado sugere que o AIB induz o aumento do número de raízes por estaca e, em conseqüência, diminui o comprimento das mesmas. Os demais tipos fisiológicos de estacas não foram influenciados pela adição de AIB, quanto ao comprimento de raízes.

Além disso, não houve diferença significativa na produção de massa seca de raízes para os tipos fisiológicos de estacas.

A produção de massa seca de raízes para todos os tipos fisiológicos de estacas não foi influenciada significativamente pela adição isolada de AIB ou em conjunto com B. Conforme BLAKESLEY et al. (1991), a ação da auxina ocorre pouco antes do primeiro evento de formação do primórdio radicular (desdiferenciação celular e formação de um locus meristemático), demonstrando que ela atua na indução da formação de raízes e não no seu posterior desenvolvimento.

\section{CONCLUSÃO}

A aplicação isolada de Zn e B nas estacas não influencia o seu enraizamento. $O$ condicionamento de estacas de ramos "do ano" basais finas com AIB afeta, negativamente, o percentual de enraizamento e, positivamente, o número de raízes por estaca.

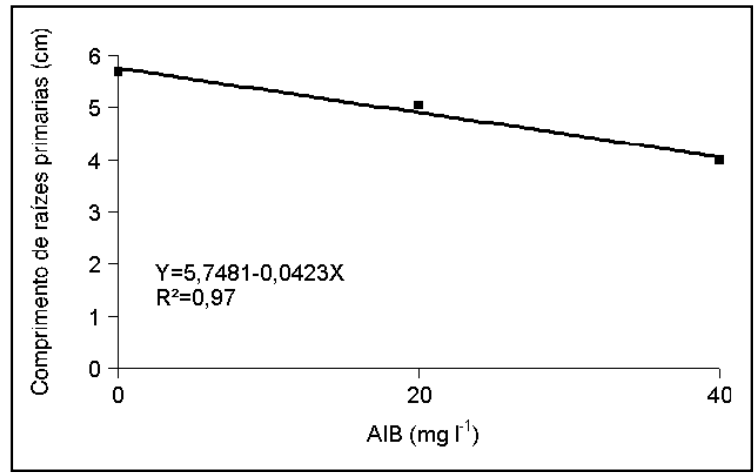

Figura 3- Efeito da aplicação de AIB, na ausência de B, no comprimento de raízes primárias de estacas de ramos "do ano" medianas de plátano (Platanus acerifolia Ait.), coletadas na época IV (julho/96). Santa Maria, RS, 1998.

\section{REFERÊNCIAS BIBLIOGRÁFICAS}

ALVARENGA, L.R., CARVALHO, V.D. Uso de substâncias promotoras de enraizamento de estacas frutíferas. Informe Agropecuário, Belo Horizonte, v. 9, n. 101, p. 47-59, 1983.

BEZERRA, J.E.F, LEDERMAN, I.E, SILVA, M.F.F, $\boldsymbol{e}$ t al. Enraizamento de estacas herbáceas de acerola com ácido indol-butírico e ácido alfa-naftaleno acético a baixas concentrações em duas épocas. Revista Brasileira de Fruticultura, Cruz das Almas, v. 45, n. 1, p. 1-6, 1992.

BLAKESLEY, D., WESTON, G.D., HALL, J.F. The role of endogenous auxin in root initiation. Plant Growth Regulation, Netherlands, v. 10, p. 341-353, 1991.

FACHINELlO, J.C., HOFFMAN, A., NACHTIGAL, J.C. $\boldsymbol{e}$ t $\boldsymbol{a}$. Propagação de plantas frutíferas de clima temperado. Pelotas: UFPEL, 1994, 179 p.

FACHINELlO, J.C., KERSTEN, E., JÚNIOR, P.S. Efeito do ácido indol-butírico no enraizamento do estacas lenhosas e obtenção de mudas de pessegueiro. In: VII CONGRESSO DE FRUTICULTURA, 1984, Florianópolis, SC: Anais... Florianópolis: EMPASC, 1984. 1598 p. p. 1088-1096.

FERRI, M. G. Fisiologia Vegetal. São Paulo: EPU, 1979. V. 2. $401 \mathrm{p}$.

GAUCH, H.G., DUGGER, W.M. JR. The physiological action of boron in higher plants: review and interpretation. Maryland: University of Maryland AES Bull, 1954. 43 p. Boletim Técnico, 80.

HENRY, P.A., BLAZICH, F.A., HINESLEY, L.E. Influence of stock fertility on adventicious rooting of stem cuttings Journal of American Society Horticulture Science, Alexandria, v. 117, p. 568-570, 1992.

KERSTEN, E. Efeito do Boro, Zinco e Ácido Indol-butírico no enraizamento de estacas de dois cultivares de ameixeira (Prunus salicina, Lindl.). Piracicaba - SP, 1990. 111 p. Tese (Doutorado em Agronomia) - Curso de Pós-graduação em Agronomia, Escola Superior Luiz de Queiroz, 1990.

LAZZARI, M., FORTUNATO, R.P., NICOLOSO, F.T. Estudo sobre enraizamento de estacas de pessegueiro (Prunus persica L.). In: III JORNADA INTEGRADA DE PESQUISA, 
EXTENSÃO E ENSINO, 1996, Santa Maria. Anais... Santa Maria: Universidade Federal de Santa Maria, 1996a, 1036 p., p. 388

LAZZARI, M., FORTUNATO, R.P., NICOLOSO, F.T. Efeito do boro, zinco e ácido indolbutírico no enraizamento de estacas de salso bugre (Salix humboldtidiana). In: III JORNADA INTEGRADA DE PESQUISA, EXTENSÃO E ENSINO, 1996, Santa Maria. Anais... Santa Maria: Universidade Federal de Santa Maria, 1996b. 1036 p., p. 391.

LEONARDIS, R.F.J. Libro del Arbol: Esencias florestales no autóctonas cultivadas en la Argentina de aplicacion ornamental y/o industrial. Buenos Aires: Celulosa Argentina, 1977. V. 3. 355 p.

MENGEL, K., KIRKBY, E.A. Principles of plant nutrition. Worblaufer-Bern: International Potash Institute, 1979. 579 p.

MERINO, D.M. Cortavientos en agricultura. Madrid: Mundi, $1991.79 \mathrm{p}$.

MIDDLETON, W., JARVIS, B.C., BOOTH, A. The boron requirement for roots development in stem cutting of Phaseolus aureus Roxb. New Phytology, v. 81, p. 287-291, 1978.

MISRA, A.K., JAUHARI, O.S. Root induction in layers and stem cuttings of Morus alba L. and Zizypus mauritiana Lam.; with special reference to plant growth regulators. Indian Journal of Horticulture, New Delhi, v. 27, p. 141-146, 1970.

NICOLOSO, F.T., LAZZARI M., FORTUNATO, R.P Propagação vegetativa de Platanus acerifolia Ait: (I) efeito de tipos fisiológicos das estacas e épocas de coleta no enraizamento de estacas. Ciência Rural, Santa Maria, v. 29, n. 3, p. 479-485, 1999.

ONO, E.O., RODRIGUES, J.D., PINHO, S.Z. Estudo da influência da época de coleta dos ramos no enraizamento de estacas caulinares de café (Coffea arabica L. cv. "Novo Mundo"). Ciência Agrícola, Piracicaba, v. 49, p. 29-35, 1992a.

ONO, E.O., RODRIGUES, J.D., RODRIGUES, S.D. Interações entre auxinas e boro no enraizamento de estacas de Camélia. Revista Brasileira de Fisiologia Vegetal, Londrina, v. 4, n 2, p. 107-112, 1992 b.

ONO, E.O., RODRIGUES, J.D., PINHO, S.Z., et al. Enraizamento de estacas de café cv. "Novo Mundo", submetido a tratamentos auxínicos com boro. Pesquisa Agropecuária Brasileira, Brasília, v. 28, n. 7, p. 773-777, 1993

ONO, E.O., BARROS, S.A., RODRIGUES, J.D., et al. Enraizamento de estacas de Platanus acerifolia, tratadas com auxinas. Pesquisa Agropecuária Brasileira, Brasília, v. 29, n. 9 , p. 1373-1380, 1994.

TERRA, M.M., FAHL, J.I., RIBEIRO, I.J.A, et al. Efeitos de reguladores de crescimento no enraizamento de estacas de quatro porta enxertos de videira. In: VI CONGRESSO BRASILEIRO DE FRUTICULTURA, 1981, Recife. Anais... Recife: Centro de Convenções, 1981. 1685 p. p. 1265-1271.

WANG, Q., ANDERSEN, A.S. Propagation of Hibiscus rosasinensis: relations between stock plant cultivar, age, environment and growth regulator treatments. Acta Horticulturae, Wageningen, v. 245, p. 289-309, 1989.

Ciência Rural, v. 29, n. 3, 1999. 